\title{
THE TJALLING C. KOOPMANS ECONOMETRIC THEORY PRIZE
}

Econometric Theory is proud to announce the establishment of "The Tjalling C. Koopmans Econometric Theory Prize." The prize is jointly supported by the publishers, Cambridge University Press, and Mrs. Truus Koopmans. It is named in honor of Tjalling C. Koopmans, the 1975 Nobel Laureate in economic science, whose contributions to the development of econometrics are of fundamental and lasting importance to the subject. The prize is to be awarded once every two to three years for the best article reporting original research published in Econometric Theory over that period. The selection of the winning article is to be made by the Advisory Board of the Journal and the criteria for selection is based on Tjalling Koopmans' own research which is universally admired for its rigour, its clarity and its creative strength. All articles published in Econometric Theory will be candidates for the prize except those that are authored or co-authored by the Editor and members of the Advisory Board. The prize will be accompanied by a financial award of $\$ 1,000$.

The first award of the prize is for articles published in Econometric Theory over the period 1985-1987 inclusive.

The winning article is:

"A General Approach to Serial Correlation" by C. Gourieroux, A. Monfort and A. Trognon, Econometric Theory, Vol. 1, (1985), pp. $315-340$.

The citation that accompanies the award was written by the Advisory Board and reads as follows:

"This paper is a fundamental contribution to econometric theory. It provides a general framework for analyzing systematically a variety of autoregressive models with latent variables, including nonlinear simultaneous equation models, qualitative response models, and disequilibrium models. The authors show how diverse testing and estimation problems can be handled by this approach. It can be expected that this paper, which organizes the statistical analysis of data with time dependence, will also stimulate the development of new methodology."

Mrs. Truus Koopmans and Cambridge University Press join me in congratulating the authors on this award. It is a fitting tribute to Tjalling Koopmans and the substantial part of his life that he devoted to econometric research. We hope that this award will be a stimulus to the readership of Econometric Theory and, in particular, to the younger generation of econometricians to submit their best research to the Journal.

Peter C. B. Phillips

New Haven, March 1990 